\title{
openheart High-dose versus low-dose angiotensin converting enzyme inhibitors in heart failure: systematic review and meta- analysis
}

\author{
Celina Borges Migliavaca (D) , ${ }^{1,2}$ Cinara Stein (D) , ${ }^{1}$ Verônica Colpani (D) , 1 \\ Bruna Eibel, ${ }^{3,4}$ Roberta Bgeginski, ${ }^{5}$ Marcus Vinicius Simões, ${ }^{6}$ Luiz Eduardo Rohde, ${ }^{7}$ \\ Maicon Falavigna (i) 1,2
}

\begin{abstract}
- Additional material is published online only. To view, please visit the journal online (http://dx.doi.org/10.1136/ openhrt-2019-001228)
\end{abstract}

To cite: Migliavaca CB, Stein C, Colpani V, et al. High-dose versus low-dose angiotensin converting enzyme inhibitors in heart failure: systematic review and meta-analysis. Open Heart 2020;7:e001228. doi:10.1136/ openhrt-2019-001228

Received 28 March 2020 Revised 7 June 2020 Accepted 13 July 2020

Check for updates

(C) Author(s) (or their employer(s)) 2020. Re-use permitted under CC BY-NC. No commercial re-use. See rights and permissions. Published by BMJ.

For numbered affiliations see end of article.

Correspondence to Dr Celina Borges Migliavaca; celinabm7@gmail.com

\section{ABSTRACT}

Objective To systematically review evidence comparing the effect of low-dose versus high-dose ACE inhibitors (ACEls) on all-cause and cardiovascular mortality and hospitalisation, functional capacity and side effects in patients with heart failure (HF).

Methods We searched PubMed, Embase, Cochrane CENTRAL and LILACS up to January 2019. We included randomised controlled trials (RCTs) comparing low-dose versus high-dose ACEls in adults with HF with reduced left ventricular ejection fraction (HFrEF). Study selection and data extraction were performed by two independent reviewers. Risk of bias was assessed with RoB 2.0, and quality of evidence with Grading of Recommendations Assessment, Development and Evaluation (GRADE). We conducted random effects meta-analysis and trial sequential analysis.

Results We included eight RCTs (5829 patients with HF). In comparison with low-dose ACEls, high-dose ACEls showed a non-significant effect on all-cause mortality (8 RCTs, $n=5828$, relative risk (RR) $0.95,95 \% \mathrm{Cl} 0.88$ to 1.02; moderate quality of evidence), cardiovascular mortality (6 RCTs, $\mathrm{n}=4048$, RR $0.93,95 \% \mathrm{Cl} 0.85$ to 1.01 ; moderate quality of evidence), all-cause hospitalisation (5 RCTs, $n=5394$, RR $0.95,95 \% \mathrm{Cl} 0.82$ to 1.10 ; moderate quality of evidence) and cardiovascular hospitalisation (4 RCTs, $n=5242$, RR $0.98,95 \% \mathrm{Cl} 0.83$ to 1.17 ; low quality of evidence). High-dose ACEI increased functional capacity (4 studies, $n=555$, standardised mean difference 0.38 , $95 \% \mathrm{Cl} 0.20$ to 0.55 ; low quality of evidence) and the risk of hypotension (4 RCTs, $n=3783$, RR $1.64,95 \% \mathrm{Cl} 1.30$ to 2.05; moderate quality of evidence). High-dose ACEI had no effect on dizziness ( 3 RCTs, $n=4994$, RR 1.37, 95\% Cl 0.97 to 1.93 ; low quality of evidence), but decreased the risk of cough (4 RCTs, $n=5146$, RR $0.85,95 \% \mathrm{Cl} 0.73$ to 0.98 ; moderate quality of evidence).

Conclusions The magnitude of benefit of using high dose versus low to intermediate doses of ACEls might be less than traditionally suggested in clinical guidelines. These findings might help clinicians address the complex task of HF management in a more rational and timely fashion, saving efforts to implement strategies with the greatest net clinical benefit.

\section{Key questions}

What is already known about this subject?

- ACE inhibitors (ACEIs) reduce mortality and morbidity, and they are recommended as the first line treatment for patients with chronic heart failure (HF).

- Clinical practice guidelines recommend that ACEls should be uptitrated to the maximum tolerated dose, based on the theory that higher doses would promote greater neurohormonal blockade.

- High ACEI doses may also be associated with increased rates of adverse events such as hypotension and syncope, and some studies suggested no relevant dose-response gradient between ACEls and clinical outcomes such as survival and hospitalisation.

What does this study add?

- Our study suggests that the magnitude of benefit of high-dose ACEls in comparison with low-dose ACEIs is minimal or even absent for outcomes such as mortality and hospitalisation.

- High-dose ACEls increased functional capacity and risk of hypotension, and decreased the risk of cough.

How might this impact on clinical practice?

- Our findings provide evidence about benefits and harms of different ACEI doses; this can be helpful for the management of patients with HF, and the final treatment decision should be based on shared decision making.

\section{INTRODUCTION}

Heart failure (HF) with reduced ejection fraction (HFrEF) is a high-burden disease associated with high rates of mortality and morbidity. It affects about 26 million people worldwide, and the estimated 5 -year survival rate can be as low as $50 \% .^{1-3}$

Treatment recommendations for patients with HFrEF are largely uniform across international guidelines. ACE inhibitors (ACEIs) are recommended as a first-line drug in all 
proposed treatment algorithms. ${ }^{4-8}$ Since the 1980 s, several clinical trials have consistently shown that ACEIs reduce mortality and morbidity, improve functional capacity and are associated with benefits in clinical symptoms, haemodynamic features and ventricular remodelling. ${ }^{9}{ }^{10}$

Clinical practice guidelines recommend that ACEIs should be uptitrated to the maximum tolerated dose in order to achieve better outcomes. ${ }^{4-7}$ These recommendations are based in part on the opinions of HF experts, considering the pharmacological mechanism of these drugs, assuming that higher doses would promote greater neurohormonal blockade. They are also supported by observational studies which showed that patients treated with $<50 \%$ the recommended dose might have higher risk of death and hospitalisation. ${ }^{11}$ However, high doses of ACEIs may also be associated with increased rates of adverse events such as hypotension and syncope. In addition, some reports have suggested no relevant doseresponse gradient between ACEI and clinical outcomes such as survival and hospitalisation. ${ }^{12} 13$

Considering that uncertainty remains regarding this issue, our aim was to systematically review the effect of high-dose versus low-dose ACEIs in patients with HFrEF. A systematic review of current evidence may provide additional information and increase the precision of effect estimates in order to best assist clinicians in customising treatment of patients with HF.

\section{METHODS}

\section{Protocol and registration}

This systematic review was conducted in accordance with the Cochrane Handbook for Systematic Reviews of Interventions and reported according to the Preferred Reporting Items for Systematic Reviews and MetaAnalysis. ${ }^{14} 15$ The protocol was registered at the International Prospective Register of Systematic Reviews (PROSPERO), under identification number CRD42017070397.

\section{Search strategy}

We systematically searched MEDLINE (via PubMed), Embase, Cochrane CENTRAL and LILACS from inception to January 2019. Moreover, we conducted a hand search of the reference lists of relevant articles as an additional source of studies. The following terms were used: 'angiotensin-converting enzyme inhibitors', 'dose comparison', 'low dose', 'high dose', 'heart failure' and 'randomised clinical trial'. We did not include words related to the outcomes of interest to enhance search sensitivity. The search was not restricted by language or publication date filters. We adapted the search terms to fit the requirements of each database. The complete search strategy is presented in online supplementary material 1.

\section{Eligibility criteria and outcomes of interest}

We included randomised clinical trials assessing the effect of high-dose versus low-dose ACEIs in adults (aged $>18$ years) with chronic HF of any aetiology and reduced left ventricular ejection fraction $(<50 \%)$.
We excluded preclinical studies, observational studies, systematic reviews and meta-analyses, case studies, letters, editorials and conference abstracts.

The outcomes of interest were all-cause mortality, cardiovascular mortality, all-cause hospitalisation, cardiovascular hospitalisation, functional capacity, quality of life and adverse effects. In order to define relevant clinical outcomes, we conducted a literature search and consulted a patient representative. Patients with HF attribute greater value to quality of life than to longevity. ${ }^{16}$ Accordingly, patients ascribed higher weight to functional capacity (dyspnoea, daily activities) and adverse effects and lower value to hospitalisation and mortality than healthcare professionals.

\section{Study selection and data extraction}

First, we deleted duplicates and screened titles and abstracts from the search results. Studies clearly not meeting the inclusion criteria were excluded. Then, the full text of selected references was assessed, and studies meeting the prespecified eligibility criteria were included in the review.

We then extracted relevant data from the selected studies using predesigned tables. Extracted data included methodological characteristics of the studies and outcomes of interest. The authors of the selected studies were contacted by email if full data were not available. We used each study's classification of high-dose or low-dose ACEI. When needed, data were extracted from figures or graphs using WebPlotDigitizer. ${ }^{17}$ If the study did not report the $\mathrm{SD}$, we estimated it from the $\mathrm{p}$ value or used the SD provided for the same outcome in other treatment groups in the same study.

All steps of study selection and data extraction were conducted by two independent reviewers. Disagreements regarding study selection and data extraction were resolved through consensus or by a third reviewer.

\section{Risk of bias and quality assessment}

Two independent reviewers critically appraised the included studies using RoB 2.0. ${ }^{18}$ The overall quality of evidence was assessed using the Grading of Recommendations Assessment, Development and Evaluation (GRADE) framework. ${ }^{19}$ Discrepancies in quality assessment were resolved through consensus or by a third reviewer.

\section{Data analysis}

After data extraction, pooled effect estimates were obtained by comparing the change from baseline to study end for each group (for continuous outcomes) and relative risk (for categorical outcomes) using a random effects model with the DerSimonian and Laird as variance estimator. We assessed heterogeneity using the $\mathrm{I}^{2}$ statistic. Results were presented as forest plots with point estimates and $95 \%$ CIs. Meta-analyses were conducted in R statistical software V.3.5.0, ${ }^{20}$ with package meta V.4.9-1. ${ }^{21}$

To assess the sufficiency of pooled evidence, we conducted trial sequential analysis (TSA) for the 


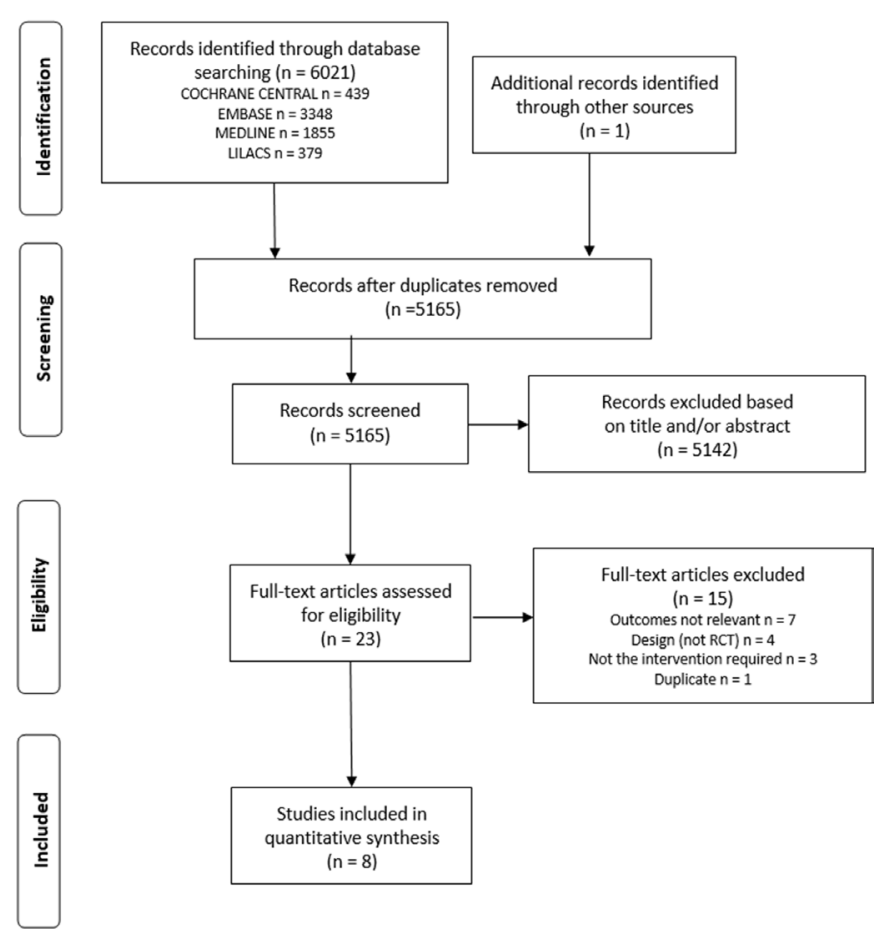

Figure 1 Flow chart of study selection.

outcomes all-cause mortality and all-cause hospitalisation. ${ }^{22}$ We estimated the required information size based on the observed rate of events in the low-dose ACEI group, the diversity suggested by the pairwise meta-analysis, an alpha level of $5 \%$, a statistical power of $80 \%$ and a relative risk reduction (RRR) of $10 \%$ and $15 \%$ for each individual outcome. We chose the RRR of $10 \%$ because we consider it a clinically relevant effect, and the RRR of $15 \%$ because this is the mortality risk reduction threshold for ACEIs in this population, according to previous meta-analysis. ${ }^{23}$ Based on the required information size, we estimated the adjusted thresholds for statistical significance and the futility boundaries when the required sample size was not reached. Trial sequential analysis were conducted in TSA V.0.9.5.10 Beta. $^{24}$

\section{RESULTS \\ Description of studies}

We identified 6021 studies in our initial search. Eight met the inclusion criteria, providing data from 5829 participants. ${ }^{121325-30}$ Figure 1 shows the flow diagram of study selection.

All studies provided reasonably clear descriptions of the participants, protocols and interventions. The mean age of participants ranged from 56 to 70 years, and the New York Heart Association functional class of HF ranged from I to IV. Captopril, enalapril, spirapril, quinapril, imidapril and lisinopril were the ACEIs studied. The definition of high dose and low dose varied across studies. Median follow-up was 6 months, ranging from 3.0 to 45.7 months. Table 1 summarises the main characteristics of the included studies.

\begin{tabular}{|c|c|c|c|c|c|c|c|c|}
\hline $\begin{array}{l}\text { Study, } \\
\text { country }\end{array}$ & $\mathbf{N}$ (total) & $\begin{array}{l}\text { Age } \\
\text { (mean } \pm S D, \\
\text { years) }\end{array}$ & $\begin{array}{l}\text { Male } \\
(\%)\end{array}$ & $\begin{array}{l}\text { Functional } \\
\text { class } \\
\text { (\%) }\end{array}$ & $\begin{array}{l}\text { LVEF } \\
\text { (mean } \pm S D, \%)\end{array}$ & $\begin{array}{l}\text { Intervention } \\
\text { (high-dose ACEI) }\end{array}$ & $\begin{array}{l}\text { Control } \\
\text { (low-dose ACEI) }\end{array}$ & $\begin{array}{l}\text { Follow-up } \\
\text { (months) }\end{array}$ \\
\hline $\begin{array}{l}\text { Clement et }\left.a\right|^{25} \\
\text { Belgium }\end{array}$ & 298 & $64.96 \pm 10.24$ & 69.10 & $\begin{array}{l}\text { I: } 12.40 \\
\text { II: } 37.95 \\
\text { III: } 49.65\end{array}$ & NR & $\begin{array}{l}\text { Captopril, } 50 \mathrm{mg} \text { twice } \\
\text { daily }\end{array}$ & $\begin{array}{l}\text { Captopril, } 25 \mathrm{mg} \text { twice } \\
\text { daily }\end{array}$ & 24 \\
\hline $\begin{array}{l}\text { The Network } \\
\text { Investigators, }^{13} \\
\text { UK }\end{array}$ & 1533 & 70 & 63.67 & $\begin{array}{l}\text { II: } 64.67 \\
\text { III: } 33 \\
\text { IV: } 2.33\end{array}$ & NR & $\begin{array}{l}\text { Enalapril, } 10 \mathrm{mg} \text { twice } \\
\text { daily }\end{array}$ & $\begin{array}{l}\text { Enalapril, } 2.5 \mathrm{mg} \text { twice } \\
\text { daily or } 5 \mathrm{mg} \text { twice } \\
\text { daily }\end{array}$ & 6 \\
\hline $\begin{array}{l}\text { Pacher et } a l^{26} \\
\text { Austria }\end{array}$ & 83 & $56 \pm 9.99$ & 83.13 & $\begin{array}{l}\text { II: } 2.40 \\
\text { III: } 79.52 \\
\text { IV: } 18.07\end{array}$ & NR & $\begin{array}{l}\text { Enalapril, } 20 \mathrm{mg} \text { twice } \\
\text { daily }\end{array}$ & $\begin{array}{l}\text { Enalapril, } 5 \mathrm{mg} \text { twice } \\
\text { daily }\end{array}$ & 12 \\
\hline $\begin{array}{l}\text { Riegger, }^{28} \\
\text { Germany }\end{array}$ & 169 & $66^{*}$ & 38.6 & $\begin{array}{l}\text { III: } 59.3 \\
\text { III: } 40.7\end{array}$ & NR & $\begin{array}{l}\text { Quinapril, } 10 \mathrm{mg} \text { twice } \\
\text { daily or } 20 \mathrm{mg} \text { twice daily }\end{array}$ & $\begin{array}{l}\text { Quinapril, } 5 \mathrm{mg} \text { twice } \\
\text { daily }\end{array}$ & 3 \\
\hline $\begin{array}{l}\text { van Veldhuisen et }\left.a\right|^{29} \\
\text { The Netherlands, } \\
\text { Belgium and Germany }\end{array}$ & 182 & $61.33 \pm 8.96$ & 79.33 & $\begin{array}{l}\text { II: } 77.67 \\
\text { III: } 22.33\end{array}$ & $33.69 \pm 8.73$ & $\begin{array}{l}\text { Imidapril, } 10 \mathrm{mg} \text { twice } \\
\text { daily }\end{array}$ & $\begin{array}{l}\text { Imidapril, } 2.5 \mathrm{mg} \text { twice } \\
\text { daily or } 5 \mathrm{mg} \text { twice } \\
\text { daily }\end{array}$ & 3 \\
\hline $\begin{array}{l}\text { Widimský et a }{ }^{30} \\
\text { Czech Republic }\end{array}$ & 152 & $57.5 \pm 10$ & 83 & $\begin{array}{l}\text { II: } 25 \\
\text { III: } 56 \\
\text { IV: } 19\end{array}$ & $28 \pm 8$ & $\begin{array}{l}\text { Spirapril, } 6 \mathrm{mg} \text { once } \\
\text { a day }\end{array}$ & $\begin{array}{l}\text { Spirapril, } 1.5 \mathrm{mg} \text { once a } \\
\text { day or } 3 \mathrm{mg} \text { once a day }\end{array}$ & 3 \\
\hline
\end{tabular}

*Median

ACEI, ACE inhibitor; LVEF, left ventricular ejection fraction; NR, not reported.; 


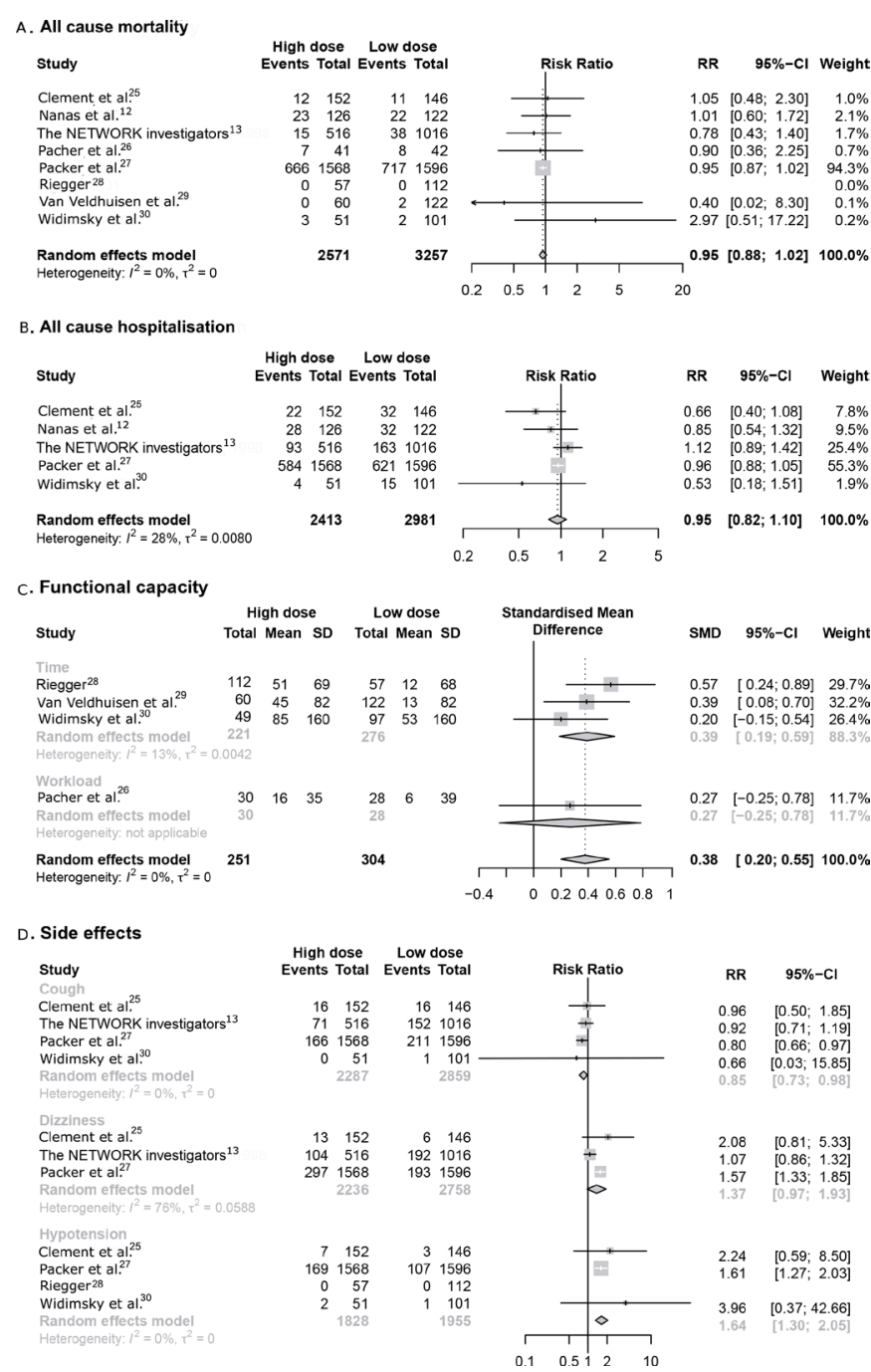

Figure 2 Effect of ACE inhibitor dose on important outcomes according to patients' perspectives. (A) Allcause mortality. (B) All-cause hospitalisation. (C) Functional capacity. (D) Adverse effects.

\section{Risk of bias assessment}

For the outcome all-cause mortality, two studies (25\%) had low risk of bias, five $(62.5 \%)$ had some concerns and one $(12.5 \%)$ had high risk of bias. For all-cause hospitalisation, two studies $(40 \%)$ had low risk of bias, two others $(40 \%)$ presented some concerns and one (20\%) had high risk of bias. Overall, studies did not report how randomisation, allocation concealment and blinding were conducted. Moreover, the lack of published or registered protocols was an issue for outcomes that could be assessed in multiple ways. A complete risk of bias assessment of the included studies is available in online supplementary material 2. Quality of evidence assessment using GRADE is fully reported in online supplementary material 3.

\section{Effects of interventions}

\section{All-cause mortality}

Eight randomised controlled trials (RCTs) ( $\mathrm{n}=5828)$ evaluating all-cause mortality in subjects with HF were included in the meta-analysis. ${ }^{12} 13$ 25-30 High-dose ACEIs were associated with a non-significant reduction in allcause mortality compared with low-dose ACEIs (RR 0.95, $95 \%$ CI 0.88 to $1.02, \mathrm{p}=0.15, \mathrm{I}^{2}=0 \%$; moderate quality of evidence) (figure 2).

\section{Cardiovascular mortality}

For the cardiovascular mortality outcome, six RCTs $(n=4048)$ were included in the meta-analysis. ${ }^{25-30}$ Highdose ACEIs were associated with a non-significant reduction in cardiovascular mortality as compared with lowdose ACEIs (RR $0.93,95 \%$ CI 0.85 to $1.01, \mathrm{p}=0.09, \mathrm{I}^{2}=0 \%$; moderate quality of evidence) (online supplementary material 4).

\section{All-cause hospitalisation}

For all-cause hospitalisation, five RCTs $(\mathrm{n}=5394)$ were included in the meta-analyses. ${ }^{12} 13252730$ High-dose ACEIs were associated with a non-significant reduction in hospitalisation when compared with low-dose ACEIs (RR 0.95, $95 \%$ CI 0.82 to $1.10, \mathrm{p}=0.46, \mathrm{I}^{2}=28 \%$; moderate quality of evidence) (figure 2).

\section{Cardiovascular hospitalisation}

Four RCTs ( $\mathrm{n}=5242)$ assessing cardiovascular hospitalisation in subjects with HF were included in the metaanalysis. ${ }^{12} 132527$ High-dose ACEIs showed a neutral effect on cardiovascular hospitalisation when compared with low-dose ACEIs (RR 0.98, 95\% CI 0.83 to $1.17, \mathrm{p}=0.86$, $\mathrm{I}^{2}=26 \%$; low quality of evidence) (online supplementary material 4).

\section{Functional capacity}

Functional capacity in subjects with HF was assessed through exercise time (in seconds) in three RCTs $(n=497)$ and through maximal workload (in watts) in one RCT $(n=58)$, which were included in the meta-analysis. ${ }^{26}$ 28-30 High-dose ACEIs increased functional capacity by 0.38 SDs (standardized mean difference $0.38,95 \%$ CI 0.20 to $0.55, \mathrm{p}<0.0001, \mathrm{I}^{2}=0 \%$; low quality of evidence), which, according to Cohen's classification, is considered a small effect (figure 2). ${ }^{31}$

\section{Side effects}

Cough was assessed in four RCTs $(\mathrm{n}=5146)$, dizziness in three RCTs $(\mathrm{n}=4994)$ and hypotension in four RCTs $(\mathrm{n}=3783) .{ }^{13} 25 \quad 27 \quad 2830$ When compared with low-dose ACEIs, high-dose ACEIs reduced the risk of cough in 15\% (RR $0.85,95 \%$ CI 0.73 to $0.98, \mathrm{p}=0.03, \mathrm{I}^{2}=0 \%$; moderate quality of evidence), did not change the risk of dizziness (RR $1.37,95 \%$ CI 0.97 to $1.93, \mathrm{p}=0.07, \mathrm{I}^{2}=76 \%$; low quality of evidence) and increased the risk of hypotension by $64 \%$ (RR 1.64, 95\% CI 1.30 to $2.05, \mathrm{p}<0.0001, \mathrm{I}^{2}=0 \%$; high quality of evidence) (figure 2).

\section{Quality of life}

Only 1 RCT, with 144 patients, assessed the outcome quality of life using the 'Living with Heart Failure' questionnaire. ${ }^{30}$ This questionnaire comprises 21 questions 
about how HF affects physical, emotional and socioeconomic aspects for patients. Higher scores indicate greater impact; the maximum score is 105 , and studies consider the minimally important difference as 5 points. ${ }^{32}$

The baseline mean score for all patients was 44 points. After 3 months, the mean change was -6 points for the high-dose ACEI group and -10 points for the low-dose ACEI group. The mean difference was -4 , with limited clinical significance, as the difference observed is smaller than the estimated minimally important difference for the outcome.

\section{Trial sequential analysis}

For an RRR of $15 \%$ in all-cause mortality, we estimated a diversity adjusted required information size (DARIS) of 3969. The meta-analysis included 5828 patients, without finding a statistically significant reduction in mortality. Therefore, we have high confidence that highdose ACEIs do not reduce the risk of mortality by $15 \%$ or more. However, the required sample size to detect an RRR of $10 \%$ is 9097 . Therefore, a risk reduction of $10 \%$ cannot be discarded with the available analysis (online supplementary material 5).

For all-cause hospitalisation, we included 5394 patients in the meta-analysis. For this outcome, risk reductions of $15 \%$ or $10 \%$ cannot be ruled out because the required sample size has not been achieved (DARIS=10372 for $15 \%$ RRR and 23717 for $10 \%$ RRR) (online supplementary material 5).

\section{DISCUSSION}

The present study is an up-to-date and comprehensive systematic review with meta-analysis of randomised clinical trials complemented with TSA focused on ascertaining the efficacy of using high-dose ACEIs on clinical outcomes in patients with HFrEF. It is relevant to mention that we used a definition of HFrEF as left ventricular ejection fraction $<50 \%$, and, therefore, patients with $\mathrm{HF}$ with midrange ejection fraction (a more recent classification) were also included. Our findings suggest that using high-dose versus low-dose ACEIs does not reduce overall mortality or hospital admissions. Although these findings must be viewed with caution, they run counter to current recommendations from clinical guidelines and HF experts to always attempt to achieve target dosing of HF drugs. ${ }^{4-8}$ As HF therapy involves multiple and complex pharmacological and non-pharmacological interventions, the concept that low versus intermediate ACEI doses on clinical outcomes might have no detrimental effect, or perhaps even no effect at all, is clinically attractive. In addition, there are several potential clinical advantages of using low to intermediate doses of ACEIs, such as reducing the risk of worsening renal function, hyperkalaemia, hypotension and non-adherence.

ACEIs decrease formation of angiotensin II by competitively inhibiting activity of ACE, the rate-limiting enzyme in formation of angiotensin II. ${ }^{33}$ However, the inhibition of circulating ACE to reduce plasma angiotensin II is probably not the sole significant action of ACEIs. Inhibition of ACE also leads to accumulation of other vasoactive peptides, such as bradykinin, which may significantly contribute to the clinical effects of this drug class. ${ }^{34}$ This hypothesis is sustained by studies that have shown ACEIs produce haemodynamic effects at either low or high doses; however, a dose-gradient effect is often observed. ${ }^{35}$

A study that addressed the question of ACEI dosing in HF was the ATLAS trial published in 1999. Parker et al suggested that high-dose ACEI reduced the hazard of the combined outcome of death and hospitalisation for any reason. However, individual outcomes were unchanged. ${ }^{27}$ Dosing of ACEIs in patients with HF has since been investigated in several studies due to continued uncertainty regarding the optimal dose. Previous literature reviews evaluated optimal dosing of ACEIs in HF with a specific focus on neurohormonal and clinical outcomes. These reviews suggested that clinicians should attempt to reach target doses and that higher doses may improve surrogate HF markers but without substantially impacting survival, corroborating our results. ${ }^{36} 37$

Recently, Khan et al published a meta-analysis of RCTs seeking to investigate the effect of different doses of ACEI and angiotensin receptor blockers on clinical outcomes and drug discontinuation in patients with $\mathrm{HF}^{38}$ This analysis incorporated six studies mixing ACEI (five reports) and angiotensin receptor blockers (one report). They observed a marginal benefit on all-cause mortality (6\% relative reduction; $\mathrm{p}=0.05$ ). Our results extend these findings, as we restricted our analysis to studies of ACEIs and used a more comprehensive search strategy, including a larger number of studies and assessing different outcomes. Overall, the magnitude of difference for mortality was similar in both reports.

Several strengths of the current analysis must be considered. We conducted a comprehensive literature search with explicit eligibility criteria and no language or date restrictions. Moreover, we systematically assessed the risk of bias on included studies and applied GRADE to determine the quality of the evidence. We also conducted TSA, which allowed us to assess the sufficiency of available data. Finally, we incorporated the perspective of patients with HF, who ascribed more value to outcomes such as quality of life and functional capacity than to hard clinical endpoints. Our data showed that high-dose ACEIs did significantly improve functional capacity, but also the risk of hypotension. Notably, high-dose ACEIs were associated with a decreased incidence of cough, which could in part be explained by a haemodynamic effect on pulmonary congestion. Importantly, dosing did not change the rate of discontinuation.

Some methodological aspects of our analysis deserve consideration. Despite our broad search, only eight studies were found in the literature, and the current meta-analysis was underpowered to detect small differences $(<10 \%)$ in most outcomes. The available studies were conducted almost 20 years ago, what may be 
associated with the fact that most had some concerns regarding risk of bias. It is also important that this may limit the external validity of these studies, since the management of HF has changed significantly over the last decades. Several important interventions, such as beta-blockers, aldosterone antagonists, neprilysin inhibitors and device therapy started to be widely used for $\mathrm{HF}$ only in the 2000s; however, ACEI uptitration still consists on a relevant clinical question nowadays. Moreover, ACEI doses and duration of therapy varied substantially among included studies, and, even though we expect the effects of ACEI to be consistent across different ACEI, we cannot ignore that there is a chance different ACEIs may have distinct effects on outcomes. Finally, many studies had short length of follow-up, limiting the assessment of outcomes such as mortality. Unfortunately, these limitations are intrinsic of the included studies and we cannot overcome them. From our understanding, these limitations show us there are still uncertainty related to ACEI uptitration in patients with HFrEF. Nevertheless, new RCTs with adequate follow-up and sample size are unlikely to arise. Real-world evidence data, based on large datasets of patients treated with current standards for HF, may provide complementary information with adequate power and external validity, adding meaningful information to better answer this question.

In conclusion, our study demonstrated that the magnitude of benefit of using high dose versus low to intermediate doses of ACEI might be minimal or even absent for hard outcomes in patients with HFrEF. High-dose ACEI improved functional capacity and decreased the incidence of cough, but increased the risk of hypotension. Physicians that care for patients with HF are facing huge challenges to implement multiple interventions (combinations of different drugs, devices and other nonpharmacological strategies) that have unquestioned efficacy. Although we acknowledge that uncertainty remains regarding the optimal dosing of ACEI, we believe that our results, taken together with previous reports, might help address these challenges in a more rational and timely fashion and help physicians implement those interventions with the greatest net clinical benefit.

\section{Author affiliations}

${ }^{1}$ Institute for Education and Research, Hospital Moinhos de Vento (HMV), Porto Alegre, RS, Brazil

${ }^{2}$ Programa de Pós-Graduação em Epidemiologia, Universidade Federal do Rio Grande do Sul, Porto Alegre, RS, Brazil

${ }^{3}$ Post Graduate Program in Health Sciences: Cardiology, Instituto de Cardiologia/ Fundação Universitária de Cardiologia (IC/FUC), Porto Alegre, RS, Brazil

${ }^{4}$ Fisioterapia, Centro Universitário da Serra Gaúcha, Caxias do Sul, RS, Brazil

${ }^{5}$ School of Kinesiology, Faculty of Health Sciences, University of Western Ontario, London, Ontario, Canada

${ }^{6}$ Cardiology Division, Universidade de São Paulo (USP), Ribeirão Preto, SP, Brazil ${ }^{7}$ Cardiovascular Division, Hospital de Clínicas de Porto Alegre (HCPA), Porto Alegre, RS, Brazil

Acknowledgements The authors would like to thank patient representative Celina Borba Figueiredo for her important insights about the patient's perspective in heart failure management.
Contributors MF, LER and VC had the idea for this article. The concepts of this manuscript were discussed among all authors. BE and RB performed the literature search. CBM and CS conducted data analysis. CBM prepared the initial draft of the manuscript. Substantial revisions were made by all authors. MF and LER supervised the project. CBM and MF are the guarantors. The corresponding author attests that all listed authors meet authorship criteria and that no others meeting the criteria have been omitted.

Funding The authors have not declared a specific grant for this research from any funding agency in the public, commercial or not-for-profit sectors.

Competing interests None declared.

Patient consent for publication Not required.

Provenance and peer review Not commissioned; externally peer reviewed.

Data availability statement All data relevant to the study are included in the article or uploaded as supplementary information.

Open access This is an open access article distributed in accordance with the Creative Commons Attribution Non Commercial (CC BY-NC 4.0) license, which permits others to distribute, remix, adapt, build upon this work non-commercially, and license their derivative works on different terms, provided the original work is properly cited, appropriate credit is given, any changes made indicated, and the use is non-commercial. See: http://creativecommons.org/licenses/by-nc/4.0/.

\section{ORCID iDs}

Celina Borges Migliavaca http://orcid.org/0000-0003-1389-2311

Cinara Stein http://orcid.org/0000-0003-1833-8221

Verônica Colpani http://orcid.org/0000-0002-7908-4213

Maicon Falavigna http://orcid.org/0000-0002-2637-6837

\section{REFERENCES}

1 Bloom MW, Greenberg B, Jaarsma T, et al. Heart failure with reduced ejection fraction. Nat Rev Dis Primers 2017;3:17058.

2 van Riet EES, Hoes AW, Wagenaar KP, et al. Epidemiology of heart failure: the prevalence of heart failure and ventricular dysfunction in older adults over time. A systematic review. Eur $J$ Heart Fail 2016;18:242-52.

3 Savarese G, Lund LH. Global public health burden of heart failure. Card Fail Rev 2017;3:7-11.

4 Ponikowski P, Voors AA, Anker SD, et al. 2016 ESC Guidelines for the diagnosis and treatment of acute and chronic heart failure: The Task Force for the diagnosis and treatment of acute and chronic heart failure of the European Society of Cardiology (ESC)Developed with the special contribution of the Heart Failure Association (HFA) of the ESC. Eur Heart J 2016;37:2129-200.

5 Yancy CW, Jessup M, Bozkurt B, et al. 2013 ACCF/AHA guideline for the management of heart failure: a report of the American College of cardiology Foundation/American heart association Task force on practice guidelines. J Am Coll Cardiol 2013;62:e147-239.

6 Ezekowitz JA, O'Meara E, McDonald MA, et al. 2017 comprehensive update of the Canadian cardiovascular Society guidelines for the management of heart failure. Can J Cardiol 2017;33:1342-433.

7 Scottish Intercollegiate Guidelines Network (SIGN). Management of chronic heart failure, 2016. Available: https://www.sign.ac.uk/sign147-management-of-chronic-heart-failure.html

8 Bocchi EA, Braga FGM, Ferreira SMA, et al. lii diretriz brasileira de insuficiência cardíaca crônica. Arq Bras Cardiol 2009;93.

9 SOLVD Investigators, Yusuf S, Pitt B, et al. Effect of enalapril on mortality and the development of heart failure in asymptomatic patients with reduced left ventricular ejection fractions. N Engl J Med 1992;327:685-91.

10 Pfeffer MA, Braunwald E, Moyé LA, et al. Effect of captopril on mortality and morbidity in patients with left ventricular dysfunction after myocardial infarction. Results of the survival and ventricular enlargement trial. The SAVE Investigators. N Engl J Med 1992;327:669-77.

11 Ouwerkerk W, Voors AA, Anker SD, et al. Determinants and clinical outcome of uptitration of ACE-inhibitors and beta-blockers in patients with heart failure: a prospective European study. Eur Heart $J$ 2017;38:1883-90.

12 Nanas JN, Alexopoulos G, Anastasiou-Nana Ml, et al. Outcome of patients with congestive heart failure treated with standard versus high doses of enalapril: a multicenter study. high enalapril dose Study Group. J Am Coll Cardiol 2000;36:2090-5.

13 Clinical outcome with enalapril in symptomatic chronic heart failure; a dose comparison. The network Investigators. Eur Heart $J$ 1998;19:481-9. 
14 Moher D, Liberati A, Tetzlaff J, et al. Preferred reporting items for systematic reviews and meta-analyses: the PRISMA statement. PLoS Med 2009;6:e1000097.

15 Training C. Cochrane handbook for systematic reviews of interventions, version 5.1.0, 2011. Available: http://handbook. cochrane.org [Accessed 22 Jan 2019].

16 Kraai IH, Vermeulen KM, Luttik MLA, et al. Preferences of heart failure patients in daily clinical practice: quality of life or longevity? Eur J Heart Fail 2013;15:1113-21.

17 Rohatgi A. WebPlotDigitizer, version 4.0, 2017. Available: https:// automeris.io/WebPlotDigitizer [Accessed 22 Jan 2019].

18 Higgins JPT, Sterne JAC, Savović J, et al. A revised tool for assessing risk of bias in randomized trials. Cochrane Database Syst Rev 2016;10:29-31.

19 Balshem H, Helfand M, Schünemann HJ, et al. GRADE guidelines: 3. rating the quality of evidence. J Clin Epidemiol 2011;64:401-6.

20 R Development Core Team. R: a language and environment for statistical computing. R foundation for statistical computing, 2008. Available: https://www.r-project.org/ [Accessed 22 Jan 2019].

21 Schwarzer G. Meta: an R package for meta-analysis. R news, 2007. Available: https://cran.r-project.org/web/packages/meta/meta.pdf [Accessed 22 Jan 2019].

22 Wetterslev J, Jakobsen JC, Gluud C. Trial sequential analysis in systematic reviews with meta-analysis. BMC Med Res Methodol 2017;17:39.

23 Thomsen MM, Lewinter C, Køber L. Varying effects of recommended treatments for heart failure with reduced ejection fraction: metaanalysis of randomized controlled trials in the ESC and ACCF/AHA guidelines. ESC Heart Fail 2016;3:235-44.

24 Thorlund K, Engstrøm J, Wetterslev J, et al. User manual for the trial sequential Metaanalysis (TSA) software. Copenhagen: Copenhagen Trial Unit, 2011. http://www.ctu.dk/tsa/files/TSA_manual.pdf

25 Clement DL, De Buyzere M, Tomas M, et al. Long-term effects of clinical outcome with low and high dose in the captopril in heart insufficient patients study (chips). Acta Cardiol 2000;55:1-7.

26 Pacher R, Stanek B, Globits S, et al. Effects of two different enalapril dosages on clinical, haemodynamic and neurohumoral response of patients with severe congestive heart failure. Eur Heart $J$ 1996;17:1223-32.
27 Packer M, Poole-Wilson PA, Armstrong PW, et al. Comparative effects of low and high doses of the angiotensin-converting enzyme inhibitor, lisinopril, on morbidity and mortality in chronic heart failure. atlas Study Group. Circulation 1999:100:2312-8.

28 Riegger GA. Effects of quinapril on exercise tolerance in patients with mild to moderate heart failure. Eur Heart $J$ 1991;12:705-11.

29 van Veldhuisen DJ, Genth-Zotz S, Brouwer J, et al. High- versus low dose ACE inhibition in chronic heart failure: a double-blind, placebocontrolled study of imidapril. J Am Coll Cardiol 1998;32:1811-8.

30 Widimský J, Kremer HJ, Jerie P, et al. Czech and Slovak spirapril intervention study (CASSIS). A randomized, placebo and activecontrolled, double-blind multicentre trial in patients with congestive heart failure. Eur J Clin Pharmacol 1995;49:95-102.

31 Cohen J. Statistical power analysis in the behavioral sciences. Hillsdale: Lawrence Erlbaum Associates, 1988.

32 Rector TS. FDA medical device development tool (MDDT) qualification package for the Minnesota living with heart failure questionnaire (MLHFQ), 2017. Available: https://djhurij4nde4r. cloudfront.net/attachments/files/000/000/483/original/MLHFQ_FDA Medical Device Development Tool (MDDT) Qualification_Package. pdf?1516113948. [Accessed 22 JAn 2019].

33 Wong J, Patel RA, Kowey PR. The clinical use of angiotensinconverting enzyme inhibitors. Prog Cardiovasc Dis 2004;47:116-30.

34 Ceconi C, Francolini G, Olivares A, et al. Angiotensin-converting enzyme (ACE) inhibitors have different selectivity for bradykinin binding sites of human somatic ACE. Eur J Pharmacol 2007;577:1-6.

35 Rochon PA, Sykora K, Bronskill SE, et al. Use of angiotensinconverting enzyme inhibitor therapy and dose-related outcomes in older adults with new heart failure in the community. J Gen Intern Med 2004;19:676-83.

36 Roffman DS. High-versus low-dose ACE inhibitor therapy in chronic heart failure. Ann Pharmacother 2004;38:831-8.

37 Thomas S, Geltman E. What is the optimal angiotensin-converting enzyme inhibitor dose in heart failure? Congest Heart Fail 2006;12:213-8.

38 Khan MS, Fonarow GC, Ahmed A, et al. Dose of angiotensinconverting enzyme inhibitors and angiotensin receptor blockers and outcomes in heart failure: a meta-analysis. Circ Heart Fail 2017;10:e003956. 